\title{
General Approach for the Synthesis of Organic-Inorganic Hybrid Nanoparticles Mediated by Supercritical $\mathrm{CO}_{2}$
}

\author{
Sandy Moisan,§ Victor Martinez,,$\uparrow$ Patrick Weisbecker, ${ }^{\ddagger}$ François Cansell,, \\ Stefan Mecking, ${ }^{*}, \dagger$ and Cyril Aymonier ${ }^{*} \S$ \\ Contribution from the Institut de Chimie de la Matière Condensée de Bordeaux, \\ ICMCB-CNRS and ENSCPB, Université Bordeaux 1, 87 avenue du Dr. Albert Schweitzer, \\ 33608 Pessac Cedex, France, Laboratoire des Composites Thermostructuraux, \\ UMR5801 (CNRS-SNECMA-CEA-UB1), 3 allée de la Boétie, 33600 Pessac Cedex, France, \\ and Department of Chemistry, University of Konstanz, Universitätsstrasse 10,
} 78457 Konstanz, Germany

Received June 5, 2007; E-mail: aymonier@icmcb-bordeaux.cnrs.fr; stefan.mecking@uni-konstanz.de

\begin{abstract}
We report in this paper novel chemistry that addresses the problem of surfactant solubility in supercritical $\mathrm{CO}_{2}$ for metal nanoparticle synthesis. This new approach for the preparation of organicfunctionalized inorganic nanoparticles relies on the reduction of a metal precursor in a $\mathrm{CO}_{2}$-containing insoluble polymer. Reduction of the metal with $\mathrm{H}_{2}$ leads to small nanocrystals stabilized by the polymer with a relatively small polydispersity. The functionalized metal nanoparticles are recovered as a dry powder, free of any organic solvents, which can then be resuspended in an appropriate solvent. This approach limits the number of steps for the preparation of functional nanoparticles which are ready for use. To illustrate this, we report results of the preparation of palladium and silver nanoparticles of $3-5 \mathrm{~nm}$ size stabilized with hyperbranched polyamines, functionalized with perfluoroalkyl, perfluorooligoether, non-fluorinated alkyl, polysiloxane, or polyethylene glycol moieties.
\end{abstract}

\section{Introduction}

Inorganic nanoparticles with an organic functional shell ${ }^{1,2}$ have attracted much interest due to their applications as catalytic or biological materials. Beyond providing solubility and preventing aggregation, the organic shell can also induce selectivity in catalytic reactions and compatibility in physiological systems as well.

Most often, inorganic nanoparticles are prepared by solution chemistry from soluble metal precursors. ${ }^{3}$ The organic solvents used in the synthesis of lipophilic-functionalized nanoparticles are chosen to suit the synthesis process, that is, solubilize metal precursors, reducing agents and stabilizers, and prevent aggregation as well.

Supercritical $\mathrm{CO}_{2}\left(\mathrm{scCO}_{2}\right)$ has attracted much interest as an alternative medium for replacing organic solvents. $\mathrm{ScCO}_{2}$ has been promoted as a sustainable and "green" solvent because of its non-toxicity, non-flammability, and natural abundance. ${ }^{4}$ The solvent properties can be varied over a wide range with small

\footnotetext{
§ Institut de Chimie de la Matière Condensée de Bordeaux.

$\doteqdot$ Laboratoire des Composites Thermostructuraux.

$\dagger$ University of Konstanz.

(1) (a) Zhao, M.; Sun, L.; Crooks, M. R. J. Am. Chem. Soc. 1998, 120, 48774878. (b) Mecking, S.; Thomann, R.; Frey, H.; Sunder A. Macromolecules 2000, 33, 3958-3960. (c) Aymonier, C.; Schlotterbeck, U.; Antonietti, L.; Zacharias, P.; Thomann, R.; Tiller, J. C.; Mecking, S. Chem. Commun. 2002, 3018-3019.

(2) Mornet, S.; Vasseur, S.; Grasset, F.; Duguet, E. J. Mater. Chem. 2004, 14, $1-16$.

(3) Nanostructures and nanomaterials. Synthesis, properties and applications; Cao, G., Ed.; Imperial College Press: London, 2004.

(4) Beckman, E. J. Supercrit. Fluids 2004, 28, 121-191.
}

variations of pressure and temperature, and $\mathrm{CO}_{2}$ is easier to remove from reaction products than organic solvents. These specific properties have been largely exploited to synthesize supported nanoparticles or films. ${ }^{5-7}$ Nevertheless, $\mathrm{scCO}_{2}$ has been used only occasionally for the synthesis of functionalized hybrid organic-inorganic nanoparticles, due to the low solubility of many organic stabilizers in $\mathrm{scCO}_{2}{ }^{8}$ Recently, the synthesis of functional metallic nanoparticles by using the arrested precipitation method has been reported. ${ }^{9} \mathrm{ScCO}_{2}$-soluble metalorganic precursors are reduced using $\mathrm{H}_{2}$ to obtain fluorocarboncoated silver, iridium, and platinum nanoparticles with a size of 2-12 nm, which can be redispersed in acetone and fluorous solvents. Analogously, by reduction with dimethylamine borane in the presence of a fluorinated surfactant, nanoparticles of silver, palladium, and bimetallic particles of these metals were synthesized with a size ranging from 3 to $12 \mathrm{~nm} .{ }^{10}$ The formation of metal nanoparticles (silver, copper, palladium, ... in a range $3-15 \mathrm{~nm}$ ) was also extensively studied using waterin- $\mathrm{scCO}_{2}$ microemulsions. ${ }^{11}$ An alternative approach has also been reported; a $\mathrm{CO}_{2}$ carrier solution containing $\mathrm{CO}_{2}$-soluble metal precursors is sprayed into a $\mathrm{CO}_{2}$ receiving solution

(5) Watkins, J.; McCarthy, T. Chem. Mater. 1995, 7, 1991-1994.

(6) Zhang, Y.; Erkey, C. J. Supercrit. Fluids 2006, 38, 252-267.

(7) O'Neil, A.; Watkins, J. MRS Bull. 2005, 30, 967-975.

(8) Aymonier, C.; Loppinet-Serani, A.; Reverón, H.; Garrabos, Y.; Cansell, F. J. Supercrit. Fluids 2006, 38, 242-251.

(9) Shah, P. S.; Husain, S.; Johnston, K. P.; Korgel, B. A. J. Phys. Chem. B 2001, 105, 9433-9440.

(10) Kameo, A.; Yoshimura, T.; Esumi, K. Colloids Surf. A 2003, 215, 181189.

(11) Fernandez, C. A.; Wai, C. M. Small 2006, 2, 1266-1269. 


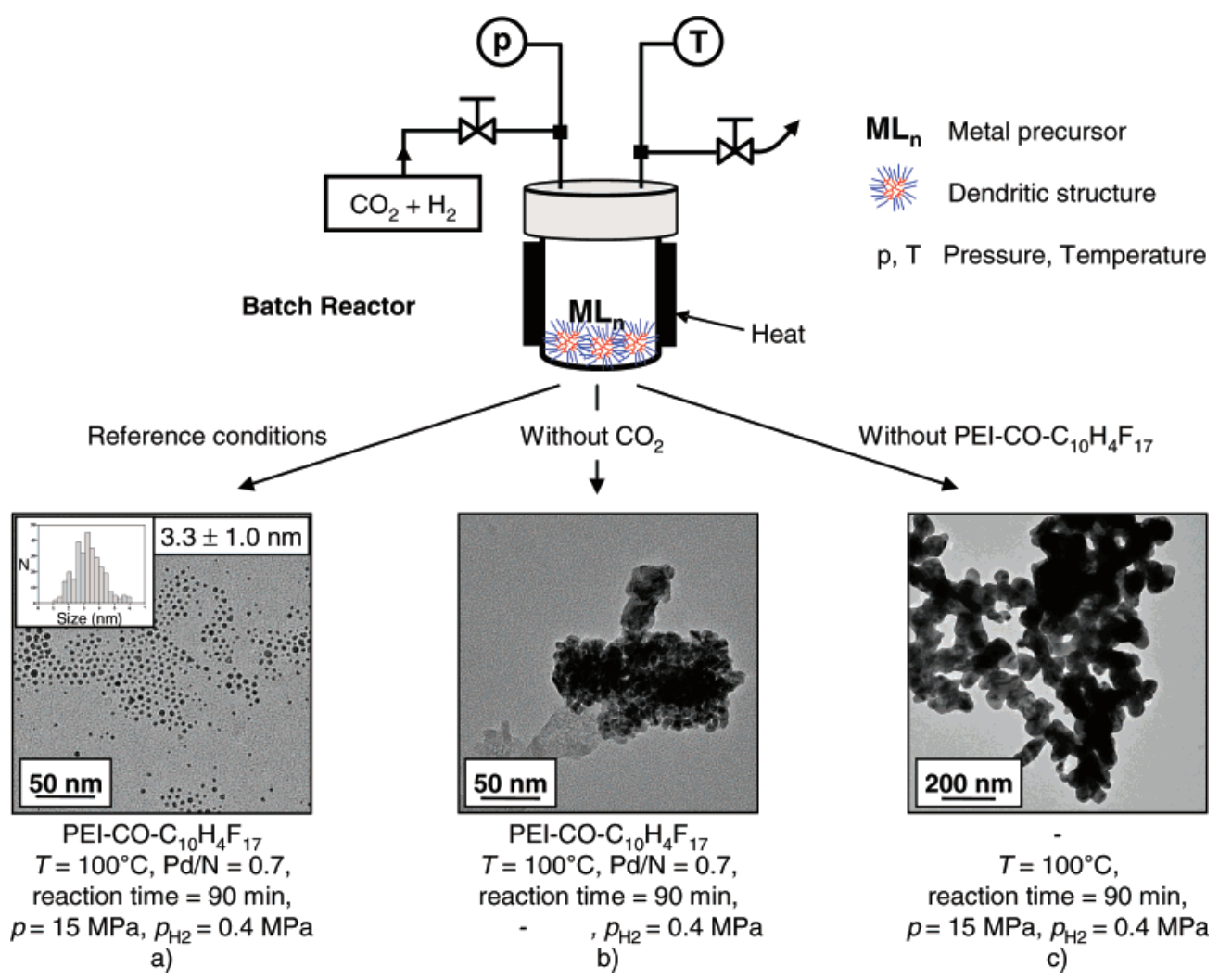

Figure 1. Experimental setup and TEM micrographs of (a) a typical sample, (b) palladium aggregates obtained without $\mathrm{CO}_{2}$, and (c) palladium aggregates obtained without polymer.

containing a reducing agent and a functionalizing agent. ${ }^{12}$ This affords silver and palladium nanoparticles $(1-15 \mathrm{~nm})$ stabilized with fluorocarbon thiols. The major limitation of these methods is the low solubility in $\mathrm{scCO}_{2}$ of stabilizing agents and, to some extent, of metal precursors. For all these reasons, a relatively low number of reports exists in this field. Indeed, only specific organic compounds are entirely or partially soluble in this medium, mainly fluorous- and siloxane-based molecules. Presently, approaches used to form stabilized nanoparticles in $\mathrm{scCO}_{2}-$ methods developed for chemistry in liquids-depend on the solubility of reactants in the medium. We now report the synthesis of organic-inorganic hybrid nanoparticles in $\mathrm{scCO}_{2}$, in which reactants need not be soluble. As the organic part, amphiphilically modified dendritic polyamines were utilized, as they are synthetically well accessible with a broad range of functionalities and effectively stabilize metal nanoparticles. The decisive factor for the selection of metal precursors and functionalizing agents was not their solubility, as in most previous studies, but the desired properties of the polymernanoparticle hybrid.

This approach is illustrated by the synthesis of palladium and silver nanoparticles stabilized with dendritic polymers functionalized with perfluoroalkyl, perfluorooligoether, polysiloxane, non-fluorinated alkyl, and oligoethylene glycol moieties. The synthesis and solubility in $\mathrm{scCO}_{2}$ of these polymers have been reported previously. ${ }^{13}$ The nanoparticle synthesis is based on the reduction of palladium acetylacetonate $\left(\mathrm{Pd}(\mathrm{acac})_{2}\right)$ and silver

(12) McLeod, M. C.; Gale, W. F.; Roberts, C. B. Langmuir 2004, 20, 70787082.

(13) Martinez, V.; Mecking, S.; Tassaing, T.; Besnard, M.; Moisan, S.; Cansell, F.; Aymonier, C. Macromolecules 2006, 39, 3978-3979. acetylacetonate $(\mathrm{Ag}(\mathrm{acac}))$ with $\mathrm{H}_{2}$ in $\mathrm{scCO}_{2}$ in the presence of the dendritic polymer.

\section{Results and Discussion}

Preparation of Hybrid Nanoparticles. Experimental conditions were chosen in such a way that the polymer and metal precursor reagent were insoluble in $\mathrm{scCO}_{2}$. The polymer used to validate our concept, a hyperbranched polyethyleneimine amide substituted with fluoroalkyl moieties at the chain ends $\left(\mathrm{PEI}-\mathrm{CO}-\mathrm{C}_{10} \mathrm{H}_{4} \mathrm{~F}_{17}\right),{ }^{13}$ is insoluble (experimental limit of detection by IR spectroscopy, around $10^{-5} \mathrm{~g} / \mathrm{g}$ of $\mathrm{CO}_{2}$ ) at $T=$ $100{ }^{\circ} \mathrm{C}$ and $p=15 \mathrm{MPa}\left(\right.$ density $=0.33 \mathrm{~g} / \mathrm{cm}^{3}$ ). The insolubility of the metallic precursor, $\mathrm{Pd}(\mathrm{acac})_{2}$, was also confirmed under these conditions.

In a typical experiment, a mixture of metal precursor, Pd$(\text { acac })_{2}$, and $\mathrm{PEI}-\mathrm{CO}-\mathrm{C}_{10} \mathrm{H}_{4} \mathrm{~F}_{17}$ (atomic $\mathrm{Pd} / \mathrm{N}$ ratio $=0.7$ ), as a powder, was placed in a stainless steel batch reactor $\left(25 \mathrm{~cm}^{3}\right)$ under $7 \mathrm{MPa}$ of $\mathrm{CO}_{2}$ and $0.4 \mathrm{MPa}$ of $\mathrm{H}_{2}$ (Figure 1, top). The reactor was heated to the reaction temperature $\left(100^{\circ} \mathrm{C}\right)$, inducing an increase of the pressure to $15 \mathrm{MPa}$. Excess $\mathrm{H}_{2}(0.4 \mathrm{MPa}$ for all experiments) was employed to ensure complete reduction of the metal precursor. After $90 \mathrm{~min}$, the reactor was depressurized. The material formed is recovered as a dry powder, which is redispersable in trifluoroethanol. Samples prepared from these colloidal solutions were characterized by transmission electron microscopy (TEM). TEM micrographs show welldispersed palladium nanoparticles with a size of $3.3 \pm 1.0 \mathrm{~nm}$ (Figure 1a). We note that silver nanoparticles can also be synthesized with a size of $6.0 \pm 1.8 \mathrm{~nm}$ using the same approach.

The aggregates presented in Figure $1 b, c$ are the result of comparative experiments performed without $\mathrm{CO}_{2}$ and without 


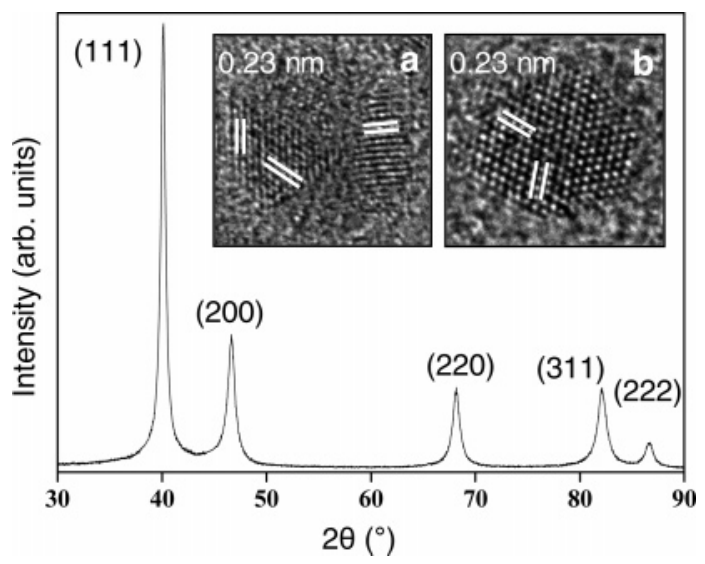

Figure 2. $\mathrm{X}$-ray diffraction pattern of palladium nanoparticles prepared with $\mathrm{PEI}-\mathrm{CO}-\mathrm{C}_{10} \mathrm{H}_{4} \mathrm{~F}_{17}\left(T=100{ }^{\circ} \mathrm{C}, \mathrm{Pd} / \mathrm{N}=0.7\right.$, reaction time $=90$ $\left.\min , p=15 \mathrm{MPa}, p_{\mathrm{H}_{2}}=0.4 \mathrm{MPa}\right)$. HRTEM micrographs of palladium nanoparticles are given as insets: (inset a) multi-twinned nanoparticle and (inset b) twinned crystal.

polymer, respectively. The first comparison (Figure 1b) proves the necessity of $\mathrm{CO}_{2}$ for the particle formation process. Figure $1 \mathrm{c}$ shows aggregates obtained in $\mathrm{scCO}_{2}$ without polymer. This proves the effectiveness of the dendritic polymer for stabilization of palladium nanoparticles.

The X-ray diffraction (XRD) pattern of the black powder (Figure 2) confirmed the face-centered cubic structure of the palladium nanoparticles $(F m 3 m)$ obtained in the reference conditions. High-resolution TEM (HRTEM) of the nanoparticles (Figure 2, inset) shows $\{111\}$ lattice fringes of a wellcrystallized multi-twinned nanoparticle (inset a) and a twinned crystal (inset b). The crystallite size calculated from the (111) reflection of the XRD pattern using the Scherrer formula is 1.5 $\mathrm{nm}$, which matches very well with the HRTEM and TEM measurements.

Influence of Experimental Parameters. The influence of reaction time on the reduction yield of $\mathrm{Pd}(\mathrm{acac})_{2}$ was studied by X-ray photoelectron spectroscopy (XPS); measurements were performed on samples obtained at different reaction times. This method allows the analysis of the chemical environment of palladium, in particular, the determination of its oxidation state. XPS analysis of the Pd $3 d$ binding energy region is shown in Figure 3a. The experimental signal was fitted with two spinorbit coupling doublets, corresponding to energy levels of $\mathrm{Pd}^{0}$ $\left[3 \mathrm{~d}_{5 / 2}(335.2 \mathrm{eV})\right.$ and $\left.3 \mathrm{~d}_{3 / 2}(340.3 \mathrm{eV})\right]$ and $\mathrm{Pd}^{\mathrm{II}}\left[3 \mathrm{~d}_{5 / 2}(337.4\right.$ $\mathrm{eV})$ and $\left.3 \mathrm{~d}_{3 / 2}(342.6 \mathrm{eV})\right]{ }^{14}$ The $\mathrm{Pd}^{0}$ contribution, which increases with increasing reaction time (Figure $3 \mathrm{~b}$ ), is proportional to the reduction of the palladium precursor. The reaction time required for complete reduction is estimated to be $90 \mathrm{~min}$.

The influence of other experimental parameters on the particle size was studied (Table 1): $\mathrm{CO}_{2}$ pressure $(p)$, reaction temperature $(T)$, and molar ratio between metallic precursor and dendritic polymer molecules $(\mathrm{Pd} / \mathrm{N})$.

The effect of $\mathrm{CO}_{2}$ pressure ( $p$ ) was investigated (entries 1-4). With pressures of $10 \mathrm{MPa}$ (entry 2) and $15 \mathrm{MPa}$ (entry 1), particle sizes and size distribution are similar. For 20 and 25 $\mathrm{MPa}$ (entries 3 and 4), the increase of pressure induces a slight increase of particle size with nearly the same size distribution. Pressure does not seem to have a significant influence on particle size in the pressure range studied.

(14) NIST X-ray Photoelectron Spectroscopy Database; National Institute of Standards and Technology: Gaithersburg, MD, 1997.
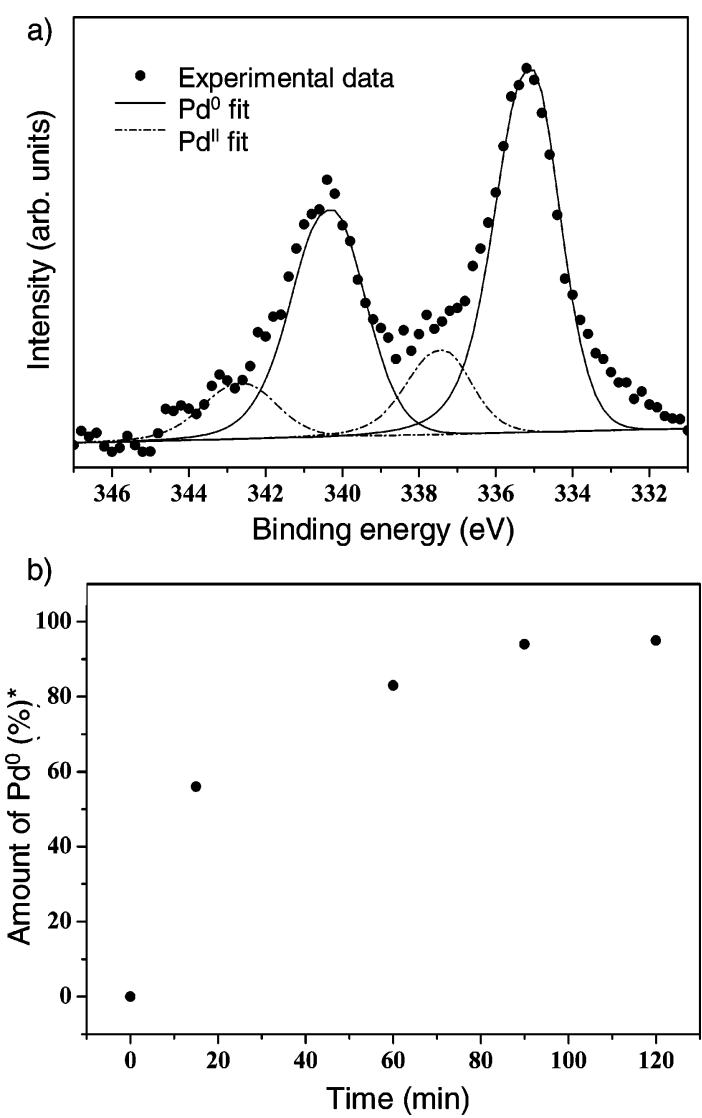

Figure 3. (a) X-ray photoelectron spectra of palladium nanoparticles $(T$ $=100{ }^{\circ} \mathrm{C}, \mathrm{Pd} / \mathrm{N}=0.7$, reaction time $=60 \mathrm{~min}, p=15 \mathrm{MPa}, p_{\mathrm{H}_{2}}=0.4$ $\mathrm{MPa}$ ) in the $\mathrm{Pd} 3 \mathrm{~d}$ binding energy region. (b) Amount of $\mathrm{Pd}^{0}(\%)$ as a function of reaction time, estimated from XPS data. $* I\left(\mathrm{Pd}^{0}\right) \times 100 /\left[I\left(\mathrm{Pd}^{0}\right)\right.$ $\left.+I\left(\mathrm{Pd}^{\mathrm{II}}\right)\right]$.

The influence of the reaction temperature $(T)$ on the particle size and size distribution was also studied (entries 1 and 5-8). For temperatures under $80{ }^{\circ} \mathrm{C}$, the formation of large crystals is observed (entry 5). Above $80^{\circ} \mathrm{C}$, stabilized nanoparticles are obtained (entries $6-8$ ). These nanoparticles seem to be slightly larger at higher temperatures. These experiments indicate that a temperature limit exists (between 60 and $80{ }^{\circ} \mathrm{C}$ ) which must be exceeded to allow sufficient diffusion of the metal precursor through the polymer.

Regarding both the results of the influence of pressure and temperature, there is not a direct correlation between solvent density and the palladium nanoparticle size.

Investigations were performed in the $\mathrm{Pd} / \mathrm{N}$ atomic ratio range of $0.2-1$ (entries 1 and $9-12$ ). We obtained nanoparticle sizes around $3 \mathrm{~nm}$; no strong changes in size are observed for the nanoparticles. This shows that particle formation is more complex than reduction of precursor to a particle in an isolated amphiphilic macromolecule as a "nanoreactor", as observed in solution under certain conditions. ${ }^{15}$ It is worth noting that the size of nanoparticles is larger than would be expected for an intramolecular synthesis in a single polymer molecule as a "reactor". This indicates that, more likely, an intermolecular process occurs.

Finally, we examined how the chemistry of the polymer would affect the formation of nanoparticles (Figure 4). We also

(15) Garamus, V. M.; Maksimova, T.; Richtering, W.; Aymonier, C.; Thomann, R.; Antonietti, L.; Mecking, S. Macromolecules 2004, 37, 7893-7900. 
Table 1. Size Dependence on Experimental Conditions of Palladium Nanoparticles Prepared in the Presence of $\mathrm{PEI}-\mathrm{CO}-\mathrm{C}_{10} \mathrm{H}_{4} \mathrm{~F}_{17}$ (Reaction Time $=90 \mathrm{Min}, p_{\mathrm{H}_{2}}=0.4 \mathrm{MPa}$ )

\begin{tabular}{|c|c|c|c|c|c|c|c|c|c|c|c|c|}
\hline & \multicolumn{12}{|c|}{ entry } \\
\hline & 1 & 2 & 3 & 4 & 5 & 6 & 7 & 8 & 9 & 10 & 11 & 12 \\
\hline$p(\mathrm{MPa})$ & 15 & 10 & 20 & 25 & 15 & 15 & 15 & 15 & 15 & 15 & 15 & 15 \\
\hline$T\left({ }^{\circ} \mathrm{C}\right)$ & 100 & 100 & 100 & 100 & 60 & 80 & 125 & 175 & 100 & 100 & 100 & 100 \\
\hline density $\left(\mathrm{g} / \mathrm{cm}^{3}\right)$ & 0.33 & 0.19 & 0.48 & 0.59 & 0.60 & 0.43 & 0.27 & 0.21 & 0.33 & 0.33 & 0.33 & 0.33 \\
\hline $\mathrm{Pd} / \mathrm{N}$ & 0.7 & 0.7 & 0.7 & 0.7 & 0.7 & 0.7 & 0.7 & 0.7 & 0.25 & 0.5 & 0.8 & 1 \\
\hline size $(\mathrm{nm})$ & $3.3 \pm 1.0$ & $3.8 \pm 1.0$ & $4.5 \pm 1.2$ & $5.2 \pm 1.1$ & $\operatorname{agg}^{a}$ & $3.8 \pm 1.0$ & $4.1 \pm 1.1$ & $4.6 \pm 0.8$ & $3.3 \pm 1.0$ & $3.3 \pm 0.6$ & $3.4 \pm 0.9$ & $2.4 \pm 0.7$ \\
\hline
\end{tabular}

${ }^{a}$ Aggregates.

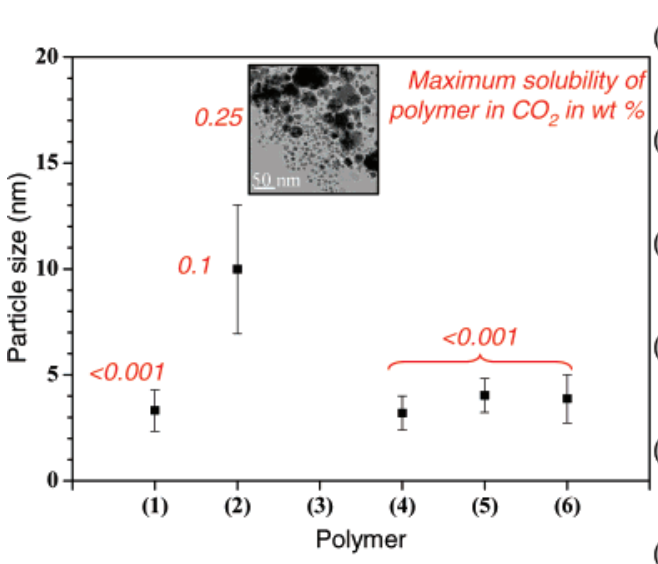

(1) $\mathrm{PEI}-\mathrm{CO}-\mathrm{C}_{10} \mathrm{H}_{4} \mathrm{~F}_{17} \equiv \mathrm{PEI}-\mathrm{CO}-\mathrm{KF}_{\mathrm{K}} \mathrm{FF} \mathrm{F}_{\mathrm{K}}$

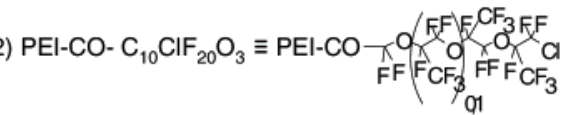

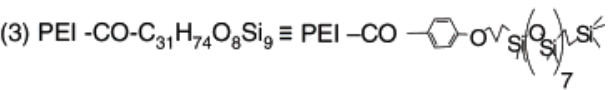

(4) $\mathrm{PEI}-\mathrm{CO}-\mathrm{C}_{10} \mathrm{H}_{21} \equiv \mathrm{PEI}-\mathrm{CO}$

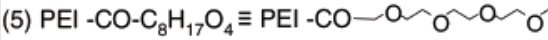

(6) $\mathrm{DAB}-\mathrm{CO}-\mathrm{C}_{10} \mathrm{H}_{4} \mathrm{~F}_{17} \equiv \mathrm{DAB}-\mathrm{CO} \underbrace{\stackrel{\mathrm{K} F \mathrm{FFFF}}{\mathrm{F} F} \mathrm{~F}}_{\mathrm{FFFFFFFF}}$

Figure 4. Size of palladium nanoparticles prepared with different amphiphilic dendritic polymers at $T=100{ }^{\circ} \mathrm{C}, \mathrm{Pd} / \mathrm{N}=0.7$, reaction time $=90 \mathrm{~min}, p$ $=15 \mathrm{MPa}, p_{\mathrm{H}_{2}}=0.4 \mathrm{MPa}$, and $\mathrm{Pd}(\mathrm{acac})_{2}$ as the metal precursor. The TEM micrograph in the inset shows a sample obtained with polymer (3), showing the very broad particle size distribution.

summarize the solubility of the different polymers in $\mathrm{scCO}_{2}$ under the reaction conditions (red numbers in Figure 4). We observed that, for polymers (1), (4), (5), and (6), which are insoluble under the experimental conditions $\left(<10^{-5} \mathrm{~g} / \mathrm{g}\right.$ of $\left.\mathrm{CO}_{2}\right)$, welldispersed nanoparticles are obtained. This is in contrast to the larger polydisperse particles which are obtained when the preparation is done with a soluble polymer in the supercritical phase.

Among the insoluble polymers, the nature of the substituents at the chain ends on the dendritic architectures has no significant effect on the nanoparticle size. This gives a wide variety of selection of polymers in designing the hybrid nanoparticles, e.g., in view of the solubility of the resulting polymer-stabilized nanoparticles in fluorous, organic, or aqueous media. In addition, the fact that the architecture of the dendritic scaffold of the macromolecule (hyperbranched polyethyleneimine $\mathrm{PEI}-\mathrm{CO}-$ $\mathrm{C}_{10} \mathrm{H}_{4} \mathrm{~F}_{17}$ or polypropyleneimine dendrimer $\mathrm{DAB}-\mathrm{CO}-\mathrm{C}_{10} \mathrm{H}_{4} \mathrm{~F}_{17}$ ) has no influence on the characteristics of palladium nanoparticles implies that easily accessible hyperbranched polymers can be employed equally well as dendrimers. ${ }^{16}$

When the polymer is partially soluble (Figure 4, polymer 3), from the TEM images the powder obtained appears as a mixture of small nanoparticles and larger structures. A possible explanation is that the reduction occurs partly in solution, as a part of the metal precursor is solubilized by the polymer, which apparently does not yield colloidally stable small particles.

Mechanism of Hybrid Nanoparticle Formation. The synthesis was monitored by direct observation in a sapphire cell. The conditions of entry 1 in Table 1 were employed with respect

(16) (a) Daniel, M.-C.; Astruc, D. Chem. Rev. 2004, 104, 293-346. (b) Sunder, A.; Heinemann, J.; Frey, H. Chem. Eur. J. 2000, 6, 2499-2506. to the heating rate $\left(3{ }^{\circ} \mathrm{C} \mathrm{min}^{-1}\right)$ followed in the stainless steel batch reactor. We observed that the reactants never become soluble in the supercritical phase during the particle preparation procedure. After introduction of $\mathrm{H}_{2}$ and $\mathrm{CO}_{2}$ into the sapphire cell, the cell was heated to $100{ }^{\circ} \mathrm{C}$. The mixture of metal precursor and polymer powder begins to melt at $50{ }^{\circ} \mathrm{C}$ and becomes liquid at $70{ }^{\circ} \mathrm{C}$, and it turns black, indicating reduction of metal precursor. This is in agreement with the observation that well-defined nanoparticles can be obtained only at temperature above $80{ }^{\circ} \mathrm{C}$ (entry 5 vs 6 , Table 1 ).

Under standard conditions, $100{ }^{\circ} \mathrm{C}$ and $15 \mathrm{MPa}$, the black liquid increases in volume, suggesting the swelling of the polymer. Reduction of the metal acetylacetonate (acac) results in the conversion of the organic ligand to Hacac, which is extracted from the liquid phase by $\mathrm{scCO}_{2}$. This is confirmed by in situ FTIR studies in a high-pressure cell, ${ }^{13}$ where Hacac was observed $\left(\bar{v}_{\mathrm{C}=\mathrm{O}} \approx 1720 \mathrm{~cm}^{-1}\right)$. After $90 \mathrm{~min}$, depressurization was performed, and $\mathrm{CO}_{2}$ bubbles were observed. A black powder was then recovered from the bottom of the cell.

On the basis of these observations, we propose the following mechanism (Figure 5) for the formation of functional hybrid nanoparticles in $\mathrm{scCO}_{2}$. As $\mathrm{scCO}_{2}$ diffuses into the powder (step 1, Figure 5) and swells the polymer, the polymer becomes liquid at the bottom of the cell (step 2, Figure 5). The liquid polymer takes up the metal precursor. Subsequent reduction affords metal nanoparticles, which are stabilized by the hyperbranched polymer. ${ }^{1 \mathrm{c}}$ This is supported by the observation, at a low temperature of $60{ }^{\circ} \mathrm{C}$, that the polymer does not swell significantly with $\mathrm{CO}_{2}$ and stays a solid; aggregates are observed (Table 1, entry 5), and a different particle formation mechanism seems to be operative. During depressurization (step 3, Figure 


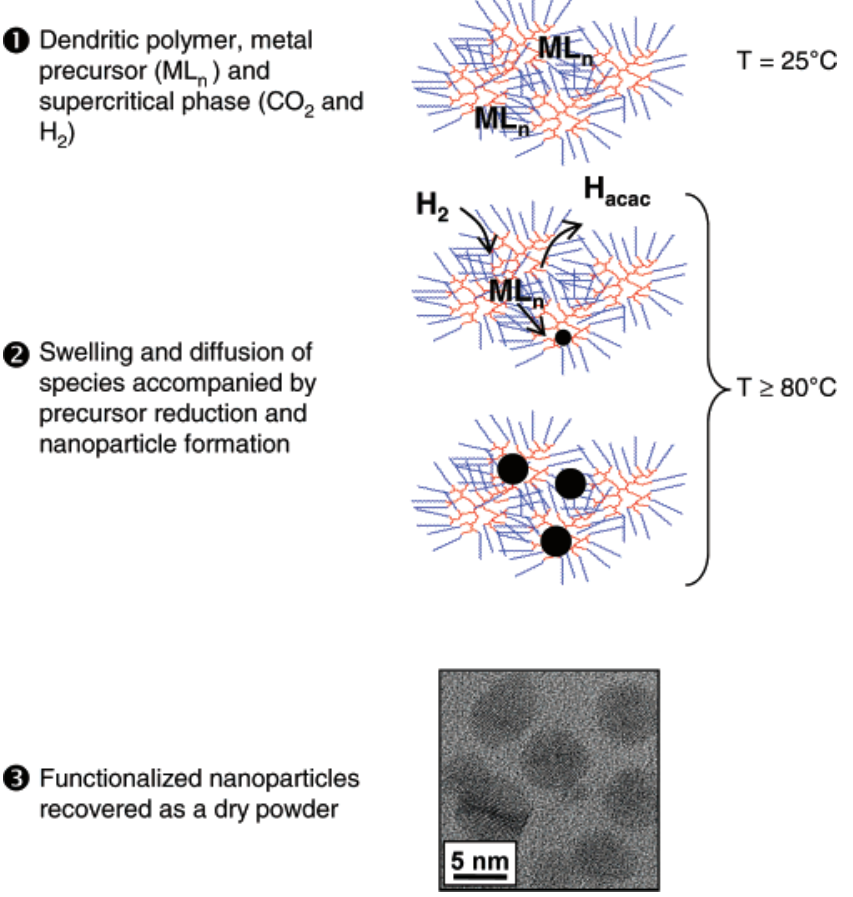

Figure 5. Proposed mechanism of formation of functional nanoparticles in $\mathrm{scCO}_{2}$.

5), $\mathrm{CO}_{2}$ is released from the powder phase, forming gas-phase bubbles, which show the presence of $\mathrm{CO}_{2}$ inside the liquid polymer. Functionalized nanoparticles are recovered as a powder, free of volatiles and side products.

As a demonstration of the catalytic properties of the nanoscale polymer-particle hybrids prepared in this study, hydrogenation of cyclohexene as a model reaction was carried out with $\mathrm{Pd} /$ PEI-CO- $\mathrm{C}_{10} \mathrm{H}_{4} \mathrm{~F}_{17}$ as a catalyst in the biphasic system trifluoroethanol/cyclohexene. Complete conversion was observed in a $2 \mathrm{~h}$ experiment, corresponding to an average turnover frequency of $10^{3}$ turnovers $\mathrm{h}^{-1}$. These preliminary results show that hybrid nanoparticles are active for catalysis.

\section{Conclusion}

In summary, we have demonstrated a novel route for a controlled synthesis of metal nanoparticles mediated by $\mathrm{scCO}_{2}$. As the method is based on swelling by $\mathrm{CO}_{2}$, the reagents employed need not be soluble in $\mathrm{CO}_{2}$. This enables the utilization of a much broader range of polymers and metal precursors compared to solution approaches. The choice of reagents can be focused on desired properties of the final products rather than solubility in the medium. The approach has been demonstrated for modified hyperbranched polyethyleneimines, which can be easily accessible. Polymer-stabilized nanoparticles free of organic solvent are obtained as easy-tohandle powders.

\section{Experimental Section}

Materials. Palladium acetylacetonate $\left(\mathrm{Pd}(\mathrm{acac})_{2}, 99 \%, 304.64 \mathrm{~g}\right.$ $\mathrm{mol}^{-1}$ ) was purchased from Aldrich and used without further purification. $\mathrm{CO}_{2}$ (TP) and $\mathrm{H}_{2}$ (Alphagaz2) were used as received from Air
Liquid. Polymers were prepared as reported previously. ${ }^{13}$ In brief, polyethyleneimine was reacted with 1 equiv (with respect to the primary amine end groups) of carbonyl-diimidazole-activated carboxylic acid (e.g., $2 \mathrm{H}, 3 \mathrm{H}, 3 \mathrm{H}$-perfluoroundecanoic acid for the synthesis of PEI$\mathrm{CO}-\mathrm{C}_{10} \mathrm{H}_{4} \mathrm{~F}_{17}$ ). In the procedure, only the primary amine end groups react selectively, such that the carboxylic acid amides are attached only at the ends of the branches. Products were characterized by ${ }^{1} \mathrm{H}$ and ${ }^{13} \mathrm{C}$ NMR and IR spectroscopy. ${ }^{13}$

General Procedures. The batch reactor is a home-made cell constructed from stainless steel. $\mathrm{H}_{2}$ is first introduced into the cell, and a high-pressure pump allows introduction of $\mathrm{CO}_{2}$ pressure. The temperature is controlled with a regulator and a thermocouple placed inside the batch reactor.

Nanoparticle Characterization. TEM observations and electron diffraction measurements were performed with a TECNAI F20 instrument operating at $200 \mathrm{kV}$ and a JEM-2200FS high-resolution TEM operating at $200 \mathrm{kV}$. Samples were prepared by evaporating a drop of nanoparticles in trifluoroethanol on a copper grid covered by a Formvar film coated with a carbon layer. Size distributions were determined by manual counting of 200 particles. Powder XRD patterns were obtained using a PANalytical X'Pert Pro MPD diffractometer with a $\theta / 2 \theta$ Bragg-Brentano geometry, a copper target tube, and an incident beam monochromator $\left(\lambda\left(\mathrm{K}_{\alpha 1}\right)=1.54059 \AA\right.$; step, $\left.0.02^{\circ}\right)$. The XPS measurements were performed on powder samples inlayed into an indium foil with an ESCALAB 220i-XL apparatus. The electron analyzer was operated at a constant pass energy of $20 \mathrm{eV}$. The sample was exposed to non-monochromatized $\mathrm{Mg} \mathrm{K} \alpha \mathrm{X}$-ray excitation (1253.6 eV with a collected area of $250 \mu \mathrm{m}$ ). The operating pressure in the analytical chamber was less than $10^{-7} \mathrm{~Pa}$. The binding energies are referenced to the $\mathrm{C} 1$ s signal due to ambient hydrocarbons $(\mathrm{C}-\mathrm{H}$ and $\mathrm{C}-\mathrm{C})$ at 284.6 $\mathrm{eV}$. Fitting of experimental signals was carried out using Shirley baselines and 70\% Gaussian/30\% Lorentzian asymmetric peaks. Each fitted Pd 3d spin-orbit coupling doublet has an intensity ratio equal to 1.5 , corresponding to the ratio $\left(\left[\operatorname{Pd} 3 \mathrm{~d}_{5 / 2}\right] /\left[\operatorname{Pd} 3 \mathrm{~d}_{3 / 2}\right]\right)$ and an energy gap of $5.3 \mathrm{eV}$.

Catalysis. Hydrogenation of $2.5 \mathrm{~mL}$ of cyclohexene was carried out under $0.8 \mathrm{MPa} \mathrm{H}_{2}$ using stabilized nanoparticles, formed under the conditions described in entry 1 of Table $1(3.7 \mathrm{mg}$, ca. $0.05 \mathrm{~mol} \%$ $\mathrm{Pd}$ ), dissolved in $5 \mathrm{~mL}$ of trifluoroethanol. After the reaction, the organic phase containing cyclohexane (hydrogenation product) was separated from the fluorinated phase, where the catalyst remained. The reaction product was identified by NMR after phase separation. The hydrogenation rate was followed by hydrogen uptake, and the accumulation of products was assessed by NMR.

Acknowledgment. Financial support by CNRS and the DFG (1388/4) within the CERC3 program is acknowledged. We thank Christine Labrugère (CECAMA-ICMCB) for XPS measurements, Stanislav Peshev for XRD measurements, and Thierry Tassaing for solubility measurements. S. Moisan and V. Martinez are grateful for research stipends by the Ministère de l'Education Nationale and the Alexander von Humboldt Foundation, respectively. We thank the reviewers for their suggestions.

\section{JA074069J}

